\title{
Promoting Service Leadership Qualities and Well-Being among University Students: Evaluation Findings in Hong Kong
}

\author{
Xiaoqin Zhu ${ }^{1} \cdot$ Daniel T. L. Shek $^{1}$ (D)
}

Received: 18 December 2020 / Accepted: 11 January 2021 / Published online: 1 February 2021

(C) The Author(s) 2021

\begin{abstract}
Service leadership education initiatives have been launched in Hong Kong to meet the emerging demand for service leaders and enhance university students' well-being through nurturing not only competence but also good character and caring disposition. However, rigorous evaluation work based on validated assessment tools has not been adequately carried out to examine whether student well-being and service leadership qualities would increase after the learning process. Using a one-group pretest-posttest design, this study investigated the effectiveness of a credit-bearing subject entitled "Service Leadership" implemented in one university in Hong Kong. Based on the responses of 114 participants (49.1\% boys, Age $=20.21 \pm 2.96$ years), it was found that students showed improvement in service leadership knowledge, attitude, and behavior after taking the subject. In addition, their life satisfaction and positive youth development attributes as indicators of well-being also significantly increased. Furthermore, the increase in well-being among students was closely associated with their attitudinal and behavioral changes but not knowledge acquisition. The present findings imply that a formal curriculum-based leadership course can be a promising way to promote student service leadership qualities and well-being.
\end{abstract}

Keywords Service leadership · Pretest-posttest $\cdot$ Leadership knowledge $\cdot$ Leadership attitude $\cdot$ Leadership behavior

\section{Introduction}

Promoting leadership qualities in university students is one of the major tasks of tertiary institutions. With the development of service economies, leadership programs in

Daniel T. L. Shek

daniel.shek@polyu.edu.hk

1 Department of Applied Social Sciences, The Hong Kong Polytechnic University, Hunghom, Hong Kong, People's Republic of China 
universities have increasingly focused on nurturing students' service mindset, values, and qualities (Haber 2006). As the service economy dominates in Hong Kong, different universities have implemented multiple leadership programs to promote students' service leadership attributes and well-being (Wong and Chandra 2015; Shek et al. 2018a). In view of the efforts and resources devoted to service leadership education in Hong Kong, it is essential to rigorously evaluate the effectiveness of these programs in terms of service leadership development and well-being enhancement. Although some evaluation work has been done in different universities (Shek and Lin 2015; Wong and Chandra 2015), most research failed to use validated assessment tools for service leadership attributes. Service leadership improvement should be objectively assessed by development in different aspects of service leadership qualities, including their understanding of the service leadership related concepts ("knowing"), endorsement of service leadership attitudes as well as service mindset ("being") and skill in practicing service leadership (“doing”). Unfortunately, no previous evaluation study has covered all these aspects simultaneously. In addition, the relationship between leadership development and changes in well-being has not been well established. To fill these research gaps, the present study attempted to evaluate the effectiveness of a service leadership subject in Hong Kong by using validated assessment tools on service leadership qualities (i.e., knowledge, attitude, and behavior). This study assessed students' changes in well-being and service leadership qualities after taking the subject. The relationship between the change in well-being and service leadership development was also explored.

\section{Importance of Service Leadership}

Leadership qualities of university students have been strongly emphasized and highly demanded in the contemporary world. Possessing leadership qualities has been generally expected by employers as a basic entry-level requirement for university graduates (Singh and Jaykumar 2019). Apart from increasing their employability and leveraging longer-term career success, the development of university students' leadership qualities also promotes their well-being. For example, leadership qualities such as competence and character strengths positively predicted subjective well-being indexed by life satisfaction, positive emotions, and happiness (e.g., Gooty et al. 2010). There were also close relationships between leadership qualities and psychological well-being defined as healthy functioning and self-actualization (Kuoppala et al. 2008). Some scholars even regarded leadership qualities as one of the indicators of psychological well-being (e.g., Shek et al. 2017). Therefore, to meet the needs of the contemporary competitive world as well as to enhance their well-being, it is of great importance to nurture leadership qualities in university students who are commonly considered as tomorrow's leaders. This maybe one of the reasons why many higher education institutions regard developing students' leadership qualities as one of their major missions (Riggio et al. 2003; Brungardt et al. 2006).

In addition, there is a remarkable structural shift in the global economy from manufacturing to service economies. For example, according to The World Bank (2019) figures, more than $77 \%$ of total GDP in the United States was contributed by service industries in 2017. In Hong Kong, the service sectors contributed approximately $90 \%$ of total GDP in the last ten years. Service economies are characterized by more 
complex human interactions involved in different service transitions as well as flatter and more decentralized organizational structures where shared decision-making and empowerment have emerged (Sartori et al. 2018; Bolden 2011). These organizational evolutions in turn challenge the conventional leadership concepts and practices which assumed that leadership was mainly occupied by only a handful of people in the higher positions. In the new service era, an effective leader should treat leadership as a relational and ethical process to improve service performance instead of merely a tool to boost authority and maximize benefits (Komives et al. 2005).

\section{Concept of Service Leadership}

To capture leadership paradigm transitions, a new leadership concept entitled "service leadership" has emerged. Grönfeldt and Strother (2006) defined it as a "collective mind-set empowering the organization to strategize its promises, design its processes, and engage its people in a proactive quest for competitive advantage" (p. 7). Likewise, Snell et al. (2015) remarked that service leadership involves "distributed practice of people-oriented leadership for service" (p. 375). These definitions highlight common key elements of service leadership, including a) distributed leadership where everyone shares leadership responsibilities, b) people-orientation which enables a leader to build and maintain positive social relationships with others, and c) service-orientation and a wide array of positive qualities that lead to high-quality services and performance.

Echoing above conceptualizations of service leadership, the Hong Kong Institute of Service Leadership \& Management (HKI-SLAM) proposed the Service Leadership Model (SLM) and defined service leadership as a process to ethically satisfy "the needs of self, others, groups, communities, systems, and environment" (Chung 2011). This model also highlighted seven core beliefs (e.g., "everyone can be a leader" and "leadership includes self-serving efforts for continuous improvement") and service mindset (i.e., a leader is a service provider), catering to the growing service economies (Shek et al. 2018a; Shek et al. 2015). Furthermore, it stressed that critical service leadership qualities should consist of generic competence (i.e., interpersonal competence, such as conflict resolution ability, and intrapersonal competence, such as emotional skills and resilience), character, and care (i.e., 3Cs).

It can be argued that the SLM integrated and went beyond the propositions of other leadership models and service leadership conceptions (Shek et al. 2015). For example, servant leadership emphasized that a leader is a servant first and should transcend one's self-interest in meeting the needs of followers (Hakanen and Van Dierendonck 2011). Other aforementioned service leadership propositions merely focused on services to others as well (Snell et al. 2015). However, such a service orientation neglects the leaders' own needs. In contrast, the SLM argued that satisfaction of leaders' own needs in ethical ways is a necessary condition for long-term well-being, continuous development, and sustainable leadership (Shek et al. 2018a).

\section{Service Leadership Education}

In accordance with the emergence of service leadership paradigms, many leadership programs in the Western context gradually shifted their emphasis from training practical leadership skills (e.g., management and communication skills) to nurturing 
character strengths and fostering service-oriented mindset and values about leadership (Haber 2006). Growing evidence has demonstrated the benefits of these leadership programs on the development of leadership capacities, such as self-confidence and social skills (Goertzen and Whitaker 2015; Roberts 2013), as well as the cultivation of service orientation and ethical values (Cress et al. 2001; Rosch and Caza 2012).

Consistent with the above movement in the West, Chinese scholars also remarked that leadership education in modern service economies should focus on not only "doing things right" with necessary practical skills (i.e., "doing") but also "doing the right things" with "a caring heart and character" (i.e., "being") (Shek et al. 2013; Shek et al. 2018a). As such, leadership education in the service economy should nurture university students to be leaders who are not only competent but also exhibit positive ethical traits, sincerity, consideration, and empathy to others, and be able to identify and care for others' needs (Shek et al. 2013).

As service industries have become the pillar of economic prosperity in Hong Kong, educators and researchers have put the above educational beliefs into practice with the guidance of the SLM framework. Specifically, HKI-SLAM and the Victor and William Fung Foundation collaboratively launched a service leadership initiative that provides financial support of $\mathrm{HK} \$ 40$ million for the eight government-funded universities in Hong Kong to develop and implement service leadership education. These universities integrated service leadership paradigm with their existing leadership programs and/or designed new service leadership programs as a part of their formal university curricula.

A typical example of the first approach is the integration of service leadership and social entrepreneurship frameworks at City University of Hong Kong (Wong and Chandra 2015). On the other hand, Hong Kong Baptist University designed three service leadership courses based on the SLM and incorporated these interdisciplinary courses in its General Education Program (Hoshmand 2015). At The Hong Kong Polytechnic University (PolyU), a credit-bearing subject entitled "Service Leadership" was developed and offered to students as a General Education course since 2012. By incorporating core tenets of the SLM (e.g., the notion of $3 \mathrm{Cs}$ and seven core beliefs) and employing an experiential teaching and learning pedagogy, the "Service Leadership" subject aimed to build up a service leadership value system in university students and cultivate their service leadership qualities (i.e., the 3Cs) (Shek et al. 2018a). This subject won the Bronze Award in the QS Reimagine Education Awards 2016. In 2018, it also won the UGC Teaching Award, the highest teaching award in Hong Kong.

\section{Effectiveness of Service Leadership Education}

Given the resources and efforts invested in service leadership education in Hong Kong, it is of paramount importance to gauge its impact through rigorous evaluation studies. First, evaluation findings can enable educators to understand whether service leadership education can foster students' service leadership qualities and promote their well-being. Findings will provide a solid foundation for further refinement and continuous development of service leadership education. In addition, as the SLM is still at its infancy, evaluation studies will contribute to theory development as well.

Unfortunately, evaluation of service leadership education in universities in Hong Kong has been far from adequate. Most of the universities only have reviewed the effect of their service leadership initiatives based on student reflection essays where 
comments on the service leadership programs can be identified (e.g., Wong and Chandra 2015). An exception is found at PolyU where multiple evaluation strategies have been utilized to conduct a systemic evaluation. Findings demonstrated that students tended to have positive changes in well-being as well as service leadership qualities after taking the "Service Leadership" subject (Shek and Lin 2015). They also considered this leadership subject helpful in enhancing their holistic development, perceived this subject as "informative" and "exciting", and gained knowledge, ability as well as happiness in learning (Shek and Lin 2015).

\section{Major Research Gaps}

Notwithstanding the positive evaluation findings at PolyU, there are still three problems that draw attention. First, the existing evaluation research has assessed service leadership attributes through generic measures that had only tentative support for psychometric properties. For example, in a previous evaluation study (Shek and Lin 2016), researchers adopted a 28-item scale and a 6-item scale to assess service leadership qualities (i.e., "self-leadership", "caring disposition", and "character strength") and beliefs, respectively. Although the two scales were developed based on the SLM and showed acceptable internal consistency in some research (Shek et al. 2018b; Shek and Lin 2016), factorial validity information of the scales was unknown. Slavec and Drnovšek (2012) remarked that "effective measurement is a cornerstone of scientific research" (p. 39). Thus, it is necessary to assess the service leadership education through validated service leadership assessment tools.

The second problem is related to what leadership qualities should be assessed. For service leadership attributes, knowledge, attitude, and behavior could be the three most important aspects that must be evaluated. Leadership knowledge is defined as one's understanding of leadership concepts, processes, and practices; it has been deemed important in shaping one's judgment and behavior when taking a leading role (Scamardo and Harnden 2007). Knowing the background, rationales, concepts, and fundamental ingredients of service leadership is a cognitive prerequisite for practicing service leadership. Thus, we must ask whether service leadership education can equip students with key knowledge of service leadership.

Service leadership attitude connotes beliefs and feelings about service leadership, which reflects one's internalized values about what an ideal leader looks like (i.e., being). An individual's personal beliefs about ideal leadership also exert influence on his or her actual leadership practice. Therefore, it is important to assess one's endorsement of the notions of the SLM (e.g., core beliefs and the notion of 3Cs), as well as one's service mindset (e.g., being sensitive to others' needs and willing to satisfy others' needs). For service leadership behavior, it is related to one's skills or practices in fulfilling leadership responsibilities (i.e., "doing"). The skills include intrapersonal skills (e.g., resilience and self-reflection), interpersonal skills (e.g., conflict resolution skills and relationship maintaining), as well as empowering and mentoring others. Thus, whether students having positive changes in how they behave as a leader represents one critical aspect in determining the effectiveness of service leadership education.

Theoretically, effective leadership education is expected to facilitate students' growth in "knowing", "being", and "doing". However, previous evaluation work on 
service leadership education at PolyU has failed to encapsulate all these aspects as outcome indicators in one single study. Most studies considered service leadership qualities in terms of "self-leadership", "caring disposition", and "character strength", which reflect a strong emphasis on service leadership "behaviors" or "skills" (Shek and Lin 2016; Shek et al. 2018b). Lin and Shek (2018) assessed both service leadership "knowledge" and "attitude" but did not include "behavior". Thus, it is necessary to encompass all the three aspects in evaluation research to draw a full picture of student changes after receiving service leadership education.

Third, well-being indicators (e.g., life satisfaction) and leadership qualities have been assessed together as primary outcome indicators of service leadership education (Shek et al. 2018b; Shek and Lin 2016). However, little work has been done to examine the relationship between service leadership development and changes in well-being. As leadership qualities have been found to be associated with well-being (e.g., Gooty et al. 2010; Kuoppala et al. 2008), acquisition of service leadership knowledge, endorsement of service leadership attitude, and improvement in leadership practice may be associated with increments in student well-being. A possible mechanism is that the development of leadership qualities may allow students to have a sense of growth and better functioning as well as overall good feelings about themselves. One study has attempted to test this possibility and found that growth in well-being was associated with the positive change in service leadership attitude but not knowledge (Lin and Shek 2018). However, this study did not consider service leadership behavior. Thus, there is a need to replicate Lin and Shek's (2018) findings and further explore whether service leadership behavior and well-being also improve hand in hand.

\section{The Present Study}

The present study attempted to address the above-mentioned research gaps. First, we evaluated the effectiveness of service leadership education using validated measurement tools for service leadership knowledge, attitude, and behavior. Besides, wellbeing measures in terms of psychological well-being and subjective well-being were used as outcome indicators in addition to service leadership qualities. We expected that students would show improvement in service leadership qualities (Hypothesis 1) and well-being (Hypothesis 2) after taking a subject on servive leadership. Second, we aimed to test the possibility that changes in leadership qualities and well-being would be significantly inter-related (Hypothesis 3 ). We addressed the research questions based on the "Service Leadership" subject offered at PolyU.

To identify student changes in well-being and service leadership qualities, the present study employed a one-group pretest-posttest design, which is a type of preexperimental design. Due to the absence of a control group, one-group pretest-posttest design has intrinsic limitations (Campbell and Stanley 1963). Nevertheless, Thyer (2002) remarked that there were several myths in the field of program evaluation, such as "you must control for the most relevant threats to internal validity" (p. 12) or "you must randomly assign clients to various control and experimental groups" (p. 13). It is practically not easy to conduct sophisticated experimental studies in an educational context. For example, material and human resources are most likely insufficient for carrying out experimental research. Also, it is hard to allocate schools or students to a control group (Shek and Zhu 2018). As such, Thyer (2002) advocated that the one- 
group pretest-posttest design is a valuable evaluation strategy that could be meaningfully employed in research fields of human services.

In fact, the one-group pretest-posttest design has been widely used in educational settings including the college contexts (Ma et al. 2019; Yang et al. 2013). For example, researchers used this research design to investigate changes in high school students after receiving a relationship education program (McElwain et al. 2016). Fagginger Auer, Hickendorff, and van Putten (2018) also used this research method to explore the effectiveness of a training program in increasing students' written strategy choices and performance. In higher education, the one-group pretest-posttest design was recommended as a useful value-added measure in evaluating what students have achieved (i.e., value added) during their study (Shek and Zhu 2018). For instance, Shek and Sun (2012) employed this method to test the effectiveness of a course aiming to promote psychosocial competence among university students. Yang et al. (2014) also used the one-group pretest-posttest design to evaluate the effectiveness of a blended course in enhancing university students' critical thinking and English literacy. Sánchez-Mendiola et al. (2015) utilized this research design to examine the knowledge acquisition among medical students after taking a Biomedical Informatics course.

\section{Methods}

\section{Overview of the "Service Leadership" Subject}

The "Service Leadership" subject was a 3-credit course that intended to deepen students' understanding of service leadership theory, cultivate their service leadership mindset and qualities, and encourage students to apply service leadership in daily life. The subject included 13 three-hour lectures, which covered a wide range of concepts and theories related to service leadership. The course content included analysis of the social and economic background of service economies, seven core beliefs of SLM, and comparisons between SLM and other leadership models. The course content also highlighted the important ingredients of effective service leadership including competence (e.g., resilience, emotional competence, relationship building, conflict resolution, and self-leadership), character (e.g., virtues and character strength), and care (e.g., empathy and active listening). Notably, not only the theoretical knowledge of service leadership was emphasized in the lectures, but an equal emphasis was placed on applying the knowledge in students' life and future career.

A student-centered teaching pedagogy was used in the subject. In addition to lecturing with multimedia stimulation and real-life examples, multiple interactive teaching methods were used. First, reflective learning was incorporated, meaning that students were required to do individual self-reflection exercises (e.g., reflection on their own situation regarding the $3 \mathrm{Cs}$ and their previous experiences in being a leader) to enhance their self-awareness (e.g., capacity, competence, and weakness) and understand how service leadership relates to their life. Second, opportunities were provided for students to undertake collaborative learning. For example, students were randomly assigned to groups and learning was facilitated through group sharing, evaluation, discussion, and presentation. Third, critical thinking was enhanced by encouraging students to think from multiple perspectives through activities like debates and critical 
evaluation of the SLM. Fourth, drawing, role-play, and games were also used to increase students' attentiveness and active learning. In summary, experiential teaching and learning approaches were expected to increase students' engagement, which would promote the achievement of intended learning outcomes. The detailed introduction of the subject is outlined elsewhere (Shek et al. 2013).

\section{Participants and Procedure}

In Semester 3 (i.e., the summer term) of the 2017-2018 academic year, the "Service Leadership" subject was offered to students at PolyU using two modes. One was implemented on PolyU campus in Hong Kong during the regular summer term (i.e., Hong Kong course hereafter). Students taking this course completed 13 lectures in seven weeks (i.e., two lectures each week from the first to the sixth week and the last lecture in the seventh week). The other was implemented as an academic component of "Cambodia Service-Learning and Leadership Summer School" (i.e., Cambodia course hereafter). Specifically, students completed the "Service Leadership" subject (and the corresponding pretest and posttest) within 10 days in Cambodia before participating in other service-learning activities there. The course content, related materials, and requirements of the Cambodia course were the same as that of the Hong Kong course.

The participants were students enrolled in the two above-mentioned courses. In the first lecture, students were invited to complete the pretest questionnaire. They were provided with a clear explanation of the confidentiality of their responses and individual written consent was obtained before data collection. Upon completion of the course, students responded to the same questions as the posttest. During the pretest and posttest, enough time was given to the students to fill in the same set of selfadministrated questionnaires in a paper-and-pencil manner. The evaluation study for the "Service Leadership" subject has been reviewed and approved by the "Human Subjects Ethics Sub-committee" (HSESC) at PolyU.

A total of 114 cases ( $49.1 \%$ boys, Age $=20.21 \pm 2.96$ years) were matched, among whom 80 and 34 participants came from the Hong Kong and Cambodia courses, respectively. Among the 80 participants taking the Hong Kong course, 42 (52.5\%) were male and $37(46.3 \%)$ were female, and one did not report the gender information. The mean age of these participants was $20.04 \pm 3.33$ years. Among the 34 participants who took the course in Cambodia, $14(41.2 \%)$ were male and $20(58.8 \%)$ were female, and the mean age was $20.62 \pm 1.83$ years.

\section{Instruments}

The questionnaire administrated in the pretest and posttest comprised measures of wellbeing and service leadership qualities as outcome indicators. First, well-being was assessed in terms of subjective and psychological well-being. Subjective well-being was indexed by life satisfaction which refers to one's cognitive perception of the overall quality of life; psychological well-being was measured as positive youth development (PYD) attributes that reflect young people's healthy functioning (Shek et al. 2017). Second, service leadership qualities measured in the present study were composed of knowledge, attitude, and behavior. 
Life satisfaction was measured by "Satisfaction with Life Scale" (SWLS) which was developed by Diener et al. (1985). The SWLS consisted of five items measured on a 6point scale ("1" = "strongly disagree", " $6 "=$ "strongly agree"). A higher score represents higher life satisfaction. The Chinese version of SWLS has shown good reliability in assessing Chinese youths' evaluation of their quality of life (Shek and Lin 2016; Shek et al. 2017). In this study, Cronbach's alphas of the scale were above .75 (see Tables 1-3), suggesting good internal reliability.

PYD attributes were measured by the 31-item abridged version of the "Chinese Positive Youth Development Scale" (CPYDS) on a 6-point scale ("1" = "strongly disagree", " $6 "=$ "strongly agree"). Out of the 15 subscales of the original CPYDS, 10 subscales were selected to assess ten PYD attributes (e.g., "cognitive competence", "emotional competence", "clear and positive identity", "resilience", etc.) (Shek and Lin 2016). These ten PYD qualities can be further classified into three higher-order factors: 1) "Cognitive-behavioral competence" that included three subscales of "cognitive competence", "behavioral competence", and "self-determination"; 2) "Positive identity" that included two subscales of "clear and positive identity" and "belief in future"; and 3) General PYD qualities that included five subscales of "social competence", "emotional competence", "moral competence", "spirituality", and "resilience". The present study used the composite scores calculated by the three higher-order factors as well as the total score of all subscales. The CPYDS possessed acceptable internal reliability (see Tables 1-3).

Service leadership knowledge was measured by the "Service Leadership Knowledge Scale" (SLK) which included 40 multiple-choice questions. The participants got one point for each correct answer and zero points for each incorrect answer. Theoretically,

Table 1 Reliability and overall changes in different outcome indicators between the pretest and posttest (whole sample, $N=114$ )

\begin{tabular}{|c|c|c|c|c|c|c|}
\hline \multirow[t]{2}{*}{ Variables } & \multicolumn{2}{|l|}{ Pretest } & \multicolumn{2}{|l|}{ Posttest } & \multirow[t]{2}{*}{$F$ value } & \multirow[t]{2}{*}{$\eta_{p}^{2}$} \\
\hline & $M(S D)$ & ${ }^{\alpha}{ }^{\alpha}$ & $M(S D)$ & $\left(\operatorname{Mean}^{\alpha}\right)^{\alpha}$ & & \\
\hline Positive Youth Development & & & & & 3.01*, a & .10 \\
\hline Cognitive-behavioral competence & $4.46(.56)$ & $.86(.40)$ & $4.61(.57)$ & $.87(.43)$ & $8.97^{* *}$ & .07 \\
\hline Positive identity & $4.37(.72)$ & $.82(.49)$ & $4.50(.81)$ & $.86(.55)$ & $5.66^{*}$ & .05 \\
\hline General positive youth development qualities & $4.44(.47)$ & $.80(.24)$ & $4.55(.50)$ & $.82(.26)$ & $7.27^{* *}$ & .06 \\
\hline $\begin{array}{l}\text { Total score of positive youth development } \\
\text { qualities }\end{array}$ & $4.43(.50)$ & $.91(.29)$ & $4.56(.52)$ & $.92(.32)$ & $10.99^{* *}$ & .09 \\
\hline Life Satisfaction & $3.99(.82)$ & $.84(.52)$ & $4.22(.82)$ & $.90(.66)$ & $13.21^{* * *}$ & .11 \\
\hline Service Leadership qualities & & & & & $\begin{array}{l}14.14^{* * * *} \\
\text { b }\end{array}$ & .28 \\
\hline Service Leadership Knowledge & $\begin{array}{l}24.65 \\
(9.54)\end{array}$ & $.94(.30)$ & $\begin{array}{l}28.99 \\
(9.43)\end{array}$ & $.98(.50)$ & $24.43^{* * *}$ & .18 \\
\hline Service Leadership Attitude & $4.73(.52)$ & $.93(.40)$ & $4.89(.59)$ & $.81(.42)$ & $10.46^{* *}$ & .08 \\
\hline Service Leadership Behavior & $4.51(.52)$ & $.92(.37)$ & $4.68(.65)$ & $.84(.41)$ & $10.77^{* *}$ & .09 \\
\hline
\end{tabular}

\# Mean inter-item correlations. ${ }^{\mathrm{a}}$ Adjusted Bonferroni value $=.013 .{ }^{\mathrm{b}}$ Adjusted Bonferroni value $=.017 . * p$ $<.05$. $* p<.01$. $* * * p<.001$ 
Table 2 Reliability and changes in different outcome indicators between the pretest and posttest (Cambodia course sample, $\mathrm{N}=34$ )

\begin{tabular}{|c|c|c|c|c|c|c|}
\hline \multirow[t]{2}{*}{ Variables } & \multicolumn{2}{|l|}{ Pretest } & \multicolumn{2}{|l|}{ Posttest } & \multirow[t]{2}{*}{$F$ value } & \multirow[t]{2}{*}{$\eta_{p}^{2}$} \\
\hline & $M(S D)$ & $\begin{array}{r}\alpha \\
\left(\text { Mean }^{\#}\right)\end{array}$ & $M(S D)$ & $\begin{array}{r}\alpha \\
\left(\operatorname{Mean}^{\#}\right)\end{array}$ & & \\
\hline Positive Youth Development & & & & & $2.94^{*}, \mathrm{a}$ & .28 \\
\hline Cognitive-behavioral competence & $4.42(.43)$ & $.73(.24)$ & $4.65(.46)$ & $.80(.32)$ & $8.56^{* *}$ & .21 \\
\hline Positive identity & $4.44(.54)$ & $.71(.34)$ & $4.65(.58)$ & $.67(.29)$ & $5.49^{*}$ & .14 \\
\hline $\begin{array}{l}\text { General positive youth development } \\
\text { qualities }\end{array}$ & $4.47(.31)$ & $.64(.20)$ & $4.59(.43)$ & $.73(.20)$ & $4.55^{*}$ & .12 \\
\hline $\begin{array}{l}\text { Total score of positive youth } \\
\text { development qualities }\end{array}$ & $4.45(.33)$ & $.82(.25)$ & $4.63(.39)$ & $.85(.27)$ & $10.37^{* *}$ & .24 \\
\hline Life Satisfaction & $4.05(.73)$ & $.76(.40)$ & $4.31(.69)$ & $.81(.47)$ & $8.72^{* *}$ & .21 \\
\hline Service Leadership qualities & & & & & $10.92^{* * * *, b}$ & .51 \\
\hline Service Leadership Knowledge & $26.79(9.57)$ & $.94(.27)$ & $30.53(8.29)$ & $.93(.27)$ & $27.24^{* * * *}$ & .45 \\
\hline Service Leadership Attitude & $4.87(.48)$ & $.89(.30)$ & $4.96(.45)$ & $.88(.29)$ & 2.53 & .07 \\
\hline Service Leadership Behavior & $4.46(.47)$ & $.86(.26)$ & $4.62(.48)$ & $.89(.32)$ & 3.40 & .09 \\
\hline
\end{tabular}

\# Mean inter-item correlations. a Adjusted Bonferroni value $=.013 .{ }^{\mathrm{b}}$ Adjusted Bonferroni value $=.017 .{ }^{*} p$ $<.05 .{ }^{*} p<.01 .{ }^{* * *} p<.001$

the score of SLK ranged between " 0 " and " 40 ". The scale was finalized based on the original long-form 200-item scale after a solid scale validation process, including

Table 3 Reliability and changes in different outcome indicators between the pretest and posttest (Hong Kong course sample, $\mathrm{N}=80$ )

\begin{tabular}{|c|c|c|c|c|c|c|}
\hline \multirow[t]{2}{*}{ Variables } & \multicolumn{2}{|l|}{ Pretest } & \multicolumn{2}{|l|}{ Posttest } & \multirow[t]{2}{*}{$F$ value } & \multirow[t]{2}{*}{$\eta_{p}^{2}$} \\
\hline & $M(S D)$ & $\begin{array}{r}\alpha \\
\left(\operatorname{Mean}^{\#}\right)\end{array}$ & $M(S D)$ & $\begin{array}{r}\alpha \\
\left(\operatorname{Mean}^{\#}\right)\end{array}$ & & \\
\hline Positive Youth Development & & & & & $1.311^{\mathrm{a}}$ & .07 \\
\hline Cognitive-behavioral competence & $4.48(.60)$ & $.88(.46)$ & $4.60(.61)$ & $.89(.47)$ & 3.75 & .05 \\
\hline Positive identity & $4.34(.78)$ & $.84(.53)$ & $4.43(.89)$ & $.89(.62)$ & 1.93 & .02 \\
\hline $\begin{array}{l}\text { General positive youth development } \\
\text { qualities }\end{array}$ & $4.42(.52)$ & $.80(.22)$ & $4.53(.52)$ & $.84(.29)$ & 3.89 & .05 \\
\hline $\begin{array}{l}\text { Total score of positive youth } \\
\text { development qualities }\end{array}$ & $4.42(.55)$ & $.93(.34)$ & $4.53(.57)$ & $.93(.35)$ & $4.74^{*}$ & .06 \\
\hline Life Satisfaction & $3.96(.86)$ & $.86(.56)$ & $4.18(.87)$ & $.92(.71)$ & $6.97^{* *}$ & .08 \\
\hline Service Leadership qualities & & & & & $9.17^{* * * *, b}$ & .26 \\
\hline Service Leadership Knowledge & $23.74(9.44)$ & $.95(.30)$ & $28.33(9.86)$ & $.98(.53)$ & $14.30^{* * * *}$ & .15 \\
\hline Service Leadership Attitude & $4.67(.52)$ & $.94(.44)$ & $4.85(.64)$ & $.95(.47)$ & $8.15^{* *}$ & .09 \\
\hline Service Leadership Behavior & $4.53(.55)$ & $.93(.42)$ & $4.71(.72)$ & $.83(.46)$ & $7.34^{* *}$ & .09 \\
\hline
\end{tabular}

${ }^{\#}$ Mean inter-item correlations. ${ }^{a}$ Adjusted Bonferroni value $=.013 .{ }^{\mathrm{b}}$ Adjusted Bonferroni value $=.017 . * p$ $<.05 . * p<.01 . * * * p<.001$ 
content validation, criterion-related validation, large-scale factorial validation using confirmatory factor analysis (CFA) (Shek et al. 2018c). The 40-item scale had good validity and reliability. These items pertained to different aspects of service leadership knowledge such as "manufacturing versus service economies in the modern world", "the importance of $3 \mathrm{Cs}$ to effective service leadership", "everyone can be a leader", "features of the service leadership theory", and so forth. Details about the conceptual framework of the SLK and the validation process can be found in Shek, Zhu, and Zhu (2018c). In the present study, the scale also showed good internal reliability (see Tables 1-3).

Service leadership attitude was assessed by the "Service Leadership Attitude Scale" (SLA) rated on a 6-point scale ("1" = "strongly disagree", "6" = "strongly agree"). Similar to SLK, the SLA was constructed based on the original long-form 132-item scale. It was trimmed and finalized after several validation studies, including a content validation study, a quasi-experimental validation study, large-scale factorial validation studies using exploratory factor analyses (EFA) and CFA (Shek and Chai 2019). According to the CFA, the 46 items in the finalized scale can be further divided into eight subscales (e.g., "people orientation", "caring disposition", "ethical role model", "self-reflection", etc.). Furthermore, the scale demonstrated good psychometric properties (Shek and Chai 2019). To control questionnaire length, the present study employed a short version of the final SLA and included half of the items (i.e., 23 items) which had the highest factor loadings in each subscale. Sample items included in the present study were "a good leader listens to his/her subordinates' views", "a leader should closely examine his/her own thoughts and behavior", and "everyone has the potential to be a leader". As depicted in Tables 1-3, the 23-item short-version SLA utilized in this study showed good internal reliability.

Service leadership behavior was assessed by the "Service Leadership Behavior Scale" (SLB), which was also rated on a 6-point scale ("1" = "strongly disagree", " $6 "=$ "strongly agree"). Like the other two service leadership assessment tools, the original SLB with 97 items has undergone content validation, an EFA analysis based on 231 participants, and large-scale factorial validation studies using EFA and CFA (Shek et al. 2019). After the validation procedure, a 38-item finalized version of SLB was obtained, which included six subscales (e.g., "self-improvement and self-reflection", "resilience", "problem-solving", etc.) and showed good validity and reliability. In the present study, we used half of the 38 items (i.e., 19 items) selected based on the highest factor loadings in each subscale. Sample items were "I learn through reflecting on my experiences", "I often try my best to help other people to overcome difficulties", and "I am able to think independently". The 19-item short-version SLB used in the present study also had good internal reliability (see Tables $1-3$ ).

\section{Data Analysis}

First, students' changes after taking the "Service Leadership" subject were examined through several repeated-measures multivariate general linear model (GLM) analyses using SPSS 25.0 (IBM Corp., Somers, NY, United States). The GLM analyses used different outcome indicators (i.e., PYD attributes, life satisfaction, service leadership 
qualities) as the dependent variables and the time (pretest versus posttest) as the independent variable. To reduce Type II errors, we employed the Bonferroni procedure to detect the significant multivariate effect of time with higher sensitivity. When the omnibus time effect was significant, follow-up univariate analyses were conducted to examine changes in each PYD composite score and service leadership quality. To understand whether students' changes varied because of the course duration (Cambodia course: ten days; Hong Kong course: seven weeks), we performed three sets of analyses using the whole sample, Cambodia course sample, and Hong Kong course sample, respectively.

Second, by using AMOS 25.0 (IBM Corp., Somers, NY, United States), a series of cross-lagged path analyses based on the whole sample were conducted to examine relationships between changes in service leadership qualities and well-being. As shown in Fig. 1, each analysis included pretest and posttest scores of two variables: service leadership quality (knowledge, attitude, or behavior) and a measure of well-being (life satisfaction or PYD total score). Each cross-lagged model included six paths indicating associations among variables: the association between the pretest scores of the two variables, temporal stability of each variable from pretest to posttest, cross-lagged effects between the two variables from pretest to posttest, and the correlation between the residuals of two posttest scores (i.e., correlated change). For example, in the crosslagged model for service leadership knowledge and life satisfaction, the six paths were as follows:

- Concurrent association (CA): correlation between pretest scores of service leadership knowledge and life satisfaction;

- Temporal stability (TS1) of service leadership knowledge from pretest to posttest;

- Temporal stability (TS2) of life satisfaction from pretest to posttest;

- Cross-lagged effect (CLE1): pretest score of service leadership knowledge (i.e., independent variable) predicted posttest score of life satisfaction (i.e., dependent variable);

- Cross-lagged effect (CLE2): pretest score of life satisfaction (i.e., independent variable) predicted posttest score of service leadership knowledge (i.e., dependent variable);

- Correlated change (CC): correlations between the residuals of posttest scores of service leadership knowledge and life satisfaction.

As all variables in one model were associated with each other, the model was a saturated model with a degree of freedom as zero and perfect fitness statistics. In each model, as other associations between the variables were statistically controlled, the correlated change can be regarded as a reliable estimation of the extent to which the within-individual changes over time in the two variables correspond to each other (Lin and Shek 2018; Allemand and Martin 2016). This statistical procedure has been often used in personality studies (e.g., Klimstra et al. 2013). The correlated changes between different personality traits can inform whether the two traits developed along a similar pathway. Thus, by applying this procedure in the present study, we can investigate whether wellbeing increased as service leadership qualities improved. 


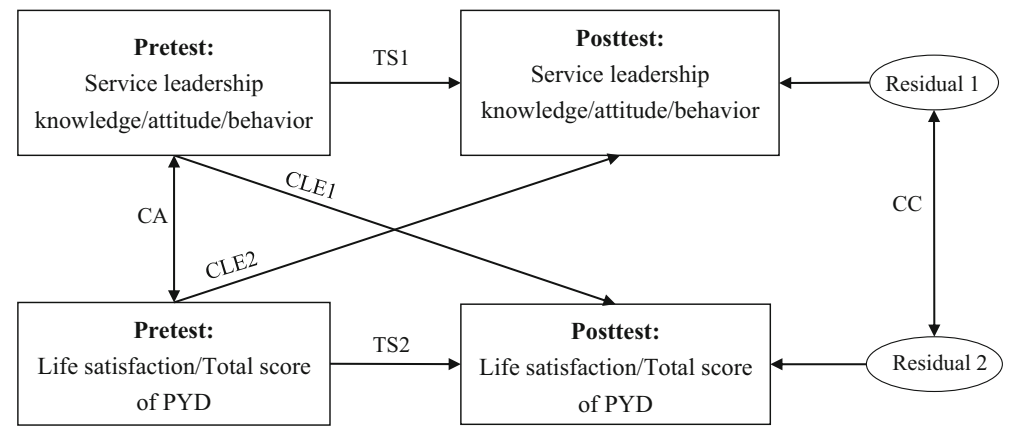

Fig. 1 Cross-lagged models among service leadership qualities and well-being indicators in pretest and posttest. PYD: Positive youth development; CA: Concurrent association; TS1: Temporal stability of service leadership quality; TS2: Temporal stability of well-being; CLE1: Cross-lagged effect of service leadership quality on well-being; CLE2: Cross-lagged effect of well-being on service leadership quality; CC: Correlated change

\section{Results}

\section{Student Changes in Service Leadership Qualities and Well-Being}

A multivariate GLM was conducted based on the whole sample to assess students' overall changes in PYD attributes after taking the subject. As shown in Table 1, the repeated-measures GML showed a significant omnibus time effect $(F(4,110)=3.01$, $p<.05, \eta^{2}{ }_{p}=.10$ ), suggesting that students had a significant improvement in their PYD attributes. As the omnibus time effect was significant, four univariate analyses were performed on each PYD composite score. Significant improvements were identified in all the four PYD outcomes with effect sizes ranging between .05 and .09 (see Table 1). The univariate analysis for life satisfaction also revealed a significant difference between pretest score and posttest score with an effect size of .11 (see Table 1). Overall speaking, students showed a significant increase in their psychological and subjective well-being from the pretest to the posttest.

The same multivariate GLM analysis was performed for service leadership qualities. As shown in Table 1, there was also a significant multivariate effect of time $\left(F(3,111)=14.14, p<.001, \eta_{p}^{2}=.28\right)$. The univariate analyses also revealed significant changes in each service leadership quality measure with effect sizes varying between .08 and .18. In general, students' service leadership attributes indexed by knowledge, attitude, and behavior improved significantly from the pretest to the posttest.

To further explore whether there were different patterns of change among students taking different modes of "Service Leadership" subject, separate analyses were performed for the Cambodia course sample $(N=34)$ and the Hong Kong course sample $(N=80)$. The results are depicted in Table 2 and Table 3, respectively. Overall speaking, an increasing trend was observed for all outcome indicators from the pretest to the posttest for both samples and the increase was significant for most of the indicators. However, the Cambodia course sample did not show significant improvement in service leadership attitude and behavior while the Hong Kong course sample did not achieve significant development in PYD measures. 


\section{Associations between the Changes in Service Leadership Quality and Well-Being}

Table 4 shows the results of six cross-lagged path analyses which were performed to test the correlated change of service leadership quality and well-being. For service leadership knowledge and life satisfaction, the correlated change was not significant $(r=-.03, p>.05)$ after statistically controlling other associations. An insignificant correlated change was found for service leadership knowledge and PYD total score $(r=.003, p>.05)$. However, correlated changes were significant in other models: service leadership attitude and life satisfaction $(\beta=.31, p<.01)$; service leadership attitude and PYD total score $(r=.32, p<.01)$; service leadership behavior and life satisfaction $(r=.48, p<.001)$; service leadership behavior and PYD total score $(r=.55$, $p<.001)$. These findings indicated that the increase in students' well-being was more likely to be associated with their attitudinal and behavioral changes but not pure knowledge acquisition.

\section{Discussion}

The rapid growth of service economies calls for effective service leaders, which drives higher institutions in Hong Kong to launch service leadership education initiatives (Shek et al. 2018a). However, there is a need to use validated measures to further understand the impact of service leadership education and whether service leadership qualities and well-being improve together. To address these questions, the present study evaluated the effectiveness of a service leadership subject implemented at a university in Hong Kong using validated service leadership scales and examined correlated changes between leadership development and growth in well-being. As expected, students showed significant improvement in their service leadership qualities (i.e., knowledge, attitude, and behavior) and

Table 4 Standardized path coefficients of cross-lagged analyses (whole sample, $\mathrm{N}=114$ )

\begin{tabular}{|c|c|c|c|c|c|c|}
\hline \multirow[t]{2}{*}{ Variables in the cross-lagged analyses } & \multicolumn{6}{|c|}{ Standardized path coefficients $(\beta)$} \\
\hline & $\mathrm{CC}$ & $\mathrm{CA}$ & TS1 & TS2 & CLE1 & CLE2 \\
\hline Service leadership knowledge and life satisfaction & -.03 & -.01 & $.51^{* * *}$ & $.64^{* * *}$ & .10 & -.08 \\
\hline Service leadership attitude and life satisfaction & $.31^{* *}$ & .12 & $.56^{* * *}$ & $.63^{* * *}$ & .08 & .01 \\
\hline Service leadership behavior and life satisfaction & $.48^{* * * *}$ & $.40^{* * * *}$ & $.61^{* * *}$ & $.62^{* * *}$ & .05 & -.06 \\
\hline $\begin{array}{l}\text { Service leadership knowledge and positive youth } \\
\text { development a }\end{array}$ & .003 & .14 & $.52^{* * *}$ & $.64^{* * * *}$ & $.17^{*}$ & -.03 \\
\hline $\begin{array}{l}\text { Service leadership attitude and positive youth development } \\
\text { a }\end{array}$ & $.32^{* *}$ & $.43^{* * *}$ & $.53^{* * *}$ & $.60^{* * * *}$ & .15 & .07 \\
\hline $\begin{array}{l}\text { Service leadership behavior and positive youth } \\
\text { development a }\end{array}$ & $.55^{* * *}$ & $.75^{* * *}$ & $.37^{* * *}$ & $.52^{* * * *}$ & .19 & $.28^{*}$ \\
\hline
\end{tabular}

Note. ${ }^{a}$ Total score of positive youth development was sued. $\mathrm{CC}=$ Correlated change; $\mathrm{CA}=\mathrm{Concurrent}$ association; TS1 = Temporal stability of service leadership quality; TS2 = Temporal stability of well-being; CLE1 = Cross-lagged effect of service leadership quality on well-being; CLE2 = Cross-lagged effect of wellbeing on service leadership quality. ${ }^{*} p<.05$. $* * p<.01$. *** $p<.001$ 
well-being (i.e., life satisfaction and PYD attributes) after taking the subject. The findings are consistent with previous research findings (Shek et al. 2018b; Lin and Shek 2018). Furthermore, an improvement in students' service leadership attitude or behavior (but not increase in knowledge) was positively linked with the increase in their life satisfaction or PYD attributes.

It has been long practiced in different disciplinary sectors to build up leadership skills (e.g., effective communication and time management) of professionals through leadership training programs. However, Shek and Ng (2017) argued that leadership education in higher education institutions should go beyond the scope by involving more students and extending the learning from promoting specific skills ("doing") to establishing a knowledge system ("knowing") and cultivating inner qualities and appropriate values ("being"). The "Service Leadership" subject may have achieved this goal, as the present evaluation findings suggest that the subject may promote students' theoretical understanding, endorsement of values and beliefs, and behavioral actions in performing service leadership.

However, we should consider the above interpretation with caution. Fundamentally, without a control group, one can argue that the observed positive changes after taking the subject might be simply due to maturation rather than course effect (Campbell and Stanley 1963). However, as previous longitudinal findings suggested that students' life satisfaction remained the same during the four-year study period in university while their psychological well-being and leadership qualities decreased in the second year and rebounded in the third year (Shek et al. 2017), it makes sense to argue that university students do not necessarily make significant gains in well-being and leadership development in a short time period (i.e., less than two months in the present study). Therefore, students' positive changes after taking the subject should be at least partially due to the course effect.

Several features of the course content and the experiential teaching and learning pedagogy might contribute to the above-mentioned positive course effect. First, the lectures covered a wide scope of conceptions (e.g., background, beliefs, and key qualities including multiple competencies, moral character, and caring to others), allowing students to have rich learning experiences and a deep understanding of service leadership concepts. Students with a better understanding of service leadership are more likely to have a positive attitude towards it and behave accordingly. This elaboration echoes the view that the quality of the program fundamentally determines the effectiveness of program implementation (Shek and Sun 2008). This may also explain the two delivery modes (two weeks versus ten days) did not make substantial differences in course effectiveness. Second, previous findings suggested that experiential and reflective learning approaches can effectively enhance learning effectiveness (Roberts and Westville 2008; Kolb 2014). In the "Service Leadership" subject, teachers adopted a student-centered teaching philosophy and employed multiple in-class activities to engage students and encourage them to experience, think, and reflect. Specifically, interactions among students and between students and the teacher in doing group discussions, reflective activities, sharing, role-play, debate, and presentation might help to promote learning effectiveness in the classroom and increase the likelihood of taking actions in daily life. In future, this conjecture needs to be empirically tested by comparing course effectiveness between the current "Service Leadership" course and other service leadership programs that adopt different teaching and learning strategies. 
In line with previous evaluation work on service leadership education in Hong Kong (Shek et al. 2018b; Lin and Shek 2018), we also found that learning experience in the "Service Leadership" subject may contribute to the enhancement of both subjective well-being (i.e., life satisfaction) and psychological well-being (i.e., PYD attributes) among university students. Most previous leadership programs did not explicitly consider promoting well-being as an intended learning outcome (Dugan and Komives 2007; Cress et al. 2001). Yet, scholars have emphasized that leadership education in university needs to take a holistic perspective to integrate the development of multiple intellectual and psychosocial competencies (Shek et al. 2016). The "Service Leadership" subject adopted this approach to foster holistic development in students. For instance, some activities were intentionally designed to increase students' awareness of their own strengths and weakness in different areas such as intrapersonal and interpersonal competencies and character strengths. Teachers encouraged students to collaboratively work on how they can improve in these areas and make action plans. With such a holistic approach, it is argued that leadership education can promote positive development in multiple domains and lead to a better life. This observation also echoes the linkages between leadership qualities and positive attributes in other aspects of life such as social connectedness, health affect, positive perspective, and well-being (Stephens and Beatty 2015; Gooty et al. 2010).

While co-curricular or extra-curricular leadership programs have long been adopted to promote leadership development among university students, credit-bearing leadership curricula were not widespread (Shek et al. 2016). The present evaluation findings suggest that curriculum-based leadership education in terms of a credit-bearing subject based on in-class teaching may also serve as a promising approach to nurture student leadership qualities and foster well-being. A formal university curriculum can benefit any students who wish to take the subject, which is consistent with the principle that "no one is left behind". This is particularly important in view of the mental health concerns in university students in Hong Kong (Lo et al. 2018, 2019). Besides, in developing a leadership curriculum, educators can intentionally enlarge the breadth and depth of course coverage to incorporate development in cognitive, psychological, and social domains. Such a design will help maximize student achievement in terms of holistic development (Shek et al. 2016).

Regarding the adoption of curriculum-based leadership education, an issue that catches the attention is the possible influence of delivery mode. In the present study, an increasing trend in outcome indicators was observed among students under the two intensive course modes (i.e., 10-day Cambodia course vs. 7-week Hong Kong course). This result is in line with previous findings showing that an intensive course design would not hinder learning achievement, instead, it may even promote learning effect (Kucsera and Zimmaro 2010; Scott 2003). Nevertheless, the improvement in service leadership attitude and behavior among the Cambodia course sample as well as the development in PYD indicators among the Hong Kong course sample did not reach a significant level. On the one hand, these results may be due to small sample size. On the other hand, different durations of the two intensive courses may exert a certain influence on course effect. As the present findings were preliminary and limited previous evidence was available regarding the effect of different intensive course patterns, more future research is needed to draw a conclusion. 
Replicating and extending Lin and Shek's (2018) findings, the present study showed that compared with knowledge acquisition, attitudinal and behavioral changes were more likely to be associated with changes in well-being. Thus, attitudinal and behavioral improvement in service leadership is a plausible mechanism leading to the promotion of student well-being. Theories of service leadership manifested a humanistic and developmental perspective in defining leadership. For instance, consistent with recent evidence that leadership was learned but not innate (Claar et al. 2016; Pandya et al. 2017), the service leadership notion emphasized human plasticity and believed in everyone's potential to be an effective service leader. When students internalize these beliefs and build up the belief that leadership attributes are not born but nurtured, they can better recognize and maximize their own potentials, and consequently view themselves and their lives more positively and optimistically. Furthermore, when students show competence, moral character, and caring in leadership practice, they can better fulfill their responsibility and enjoy positive interpersonal relationships characterized by understanding, trust, and loyalty (Wang and Cheng 2010; Hausler et al. 2017), which warrant a productive and happy life.

Nevertheless, only "knowing" more about service leadership may be unable to entail greater well-being. "Knowing", as a general intellectual capacity, has been deemed important in promoting positive leadership attitude and actual behavior (Baranowski et al. 2003). Leadership knowledge was related to self-efficacy and appraisal of one's judgment, plans, and intentions, which in turn affected leadership behavior (Ajzen 2002; Mathieson 1991). However, "knowing" alone was not enough to change behavior instantly as behavioral changes were more likely to result from changes in beliefs and attitude (Rimal 2000; Connelly et al. 2000). In the present study, some students might learn the course materials simply to fulfill assessment requirements to get a higher course grade, which was not uncommon in Chinese contexts. Thus, they may not internally transform the knowledge learned in the lectures into self-beliefs and values, either did not act out in daily practices. In this case, educators need to bear in mind that when leadership programs are adopted to promote student well-being, it is essential to facilitate attitude transformation and behavioral application in addition to knowledge accumulation.

Although the present findings are pioneering and robust in nature, several limitations of the present study need to be noted. First, we measured service leadership behavior through a self-reporting scale. Although the scale has been rigorously validated (Shek et al. 2019), it will be methodologically preferable to measure students' actual leadership practice in daily life through tools like diary or behavior checklist. Second, although the one-group pretest-posttest design has its advantages and has been widely used in higher education and youth fields, we should note the inherent limitations of the research design and interpret the observed positive changes in students with caution as we cannot completely rule out alternative explanations (e.g., maturation, test effects, etc.). For future research, it would be informative to recruit a comparison group of students who do not get the service leadership course in the same semester. Concerning the high resource-demanding of doing an experimental study, one feasible solution is to have a series of pretests and follow-up tests (i.e., multiple pretests and posttests). In fact, such modification will lead to a time-series design, a form of quasiexperimental methodology (Shek and Zhu 2018), which could better inform the 
conditions of participants' leadership qualities and well-being prior to and after taking the subject. In addition, follow-up tests could shed light on possible longterm educational effects.

Third, correlated changes between leadership qualities and well-being are correlational results, which are unable to confirm the causal effect of improvement in leadership qualities on well-being enhancement. In fact, we observed cross-lagged effects of leadership qualities on PYD as well as an effect of PYD on service leadership behavior. Thus, it is possible that there are reciprocal causal relationships between leadership development and well-being enhancement. Future research could employ a multi-wave longitudinal design and adopt latent growth curve modeling to investigate whether the development of service leadership qualities would result in higher wellbeing and/or vice versa.

Despite the above-mentioned limitations, this study provides new evidence for the effectiveness of service leadership education by using validated assessment tools. The findings suggest that university students' leadership qualities can be taught, and their well-being can be fostered through a formal curriculum-based leadership subject. This is very encouraging as educators can design and implement such subject to benefit a larger number of students. Additionally, the findings on the relationships between changes in service leadership qualities and well-being, which are pioneering in the scientific literature, will inspire researchers to carry out more in-depth studies to explore causality and underlying mechanisms.

Acknowledgments The evaluation study is financially supported by the Victor and William Fung Foundation. The preparation for this paper is supported by the Foundation and the Endowed Professorship in Service Leadership Education at The Hong Kong Polytechnic University. This paper is also financially supported by start-up grant to XZ (Project number: P0034745).

\section{Declarations}

Conflict of Interest The authors declare that the research was conducted in the absence of any commercial or financial relationships that could be construed as a potential conflict of interest.

Open Access This article is licensed under a Creative Commons Attribution 4.0 International License, which permits use, sharing, adaptation, distribution and reproduction in any medium or format, as long as you give appropriate credit to the original author(s) and the source, provide a link to the Creative Commons licence, and indicate if changes were made. The images or other third party material in this article are included in the article's Creative Commons licence, unless indicated otherwise in a credit line to the material. If material is not included in the article's Creative Commons licence and your intended use is not permitted by statutory regulation or exceeds the permitted use, you will need to obtain permission directly from the copyright holder. To view a copy of this licence, visit http://creativecommons.org/licenses/by/4.0/.

\section{References}

Ajzen, I. (2002). Perceived behavioral control, self-efficacy, locus of control, and the theory of planned behavior. Journal of Applied Social Psychology, 32(4), 665-683. https://doi.org/10.1111/j.1559-1816. 2002.tb00236.x.

Allemand, M., \& Martin, M. (2016). On correlated change in personality. European Psychologist, 21, 237253. https://doi.org/10.1027/1016-9040/a000256. 
Baranowski, T., Cullen, K. W., Nicklas, T., Thompson, D., \& Baranowski, J. (2003). Are current health behavioral change models helpful in guiding prevention of weight gain efforts? Obesity Research, 11(S10), 23S-43S. https://doi.org/10.1038/oby.2003.222.

Bolden, R. (2011). Distributed leadership in organizations: A review of theory and research. International Journal of Management Reviews, 13, 251-269. https://doi.org/10.1111/j.1468-2370.2011.00306.x.

Brungardt, C., Greenleaf, J., Brungardt, C., \& Arensdorf, J. (2006). Majoring in leadership: A review of undergraduate leadership degree programs. Journal of Leadership Education, 5(1), 4-25.

Campbell, D. T., \& Stanley, J. C. (1963). Experimental and quasi-experimental designs for research on teaching. In N. L. Gage (Ed.), Handbook of research on teaching. Rand McNally: Chicago, IL.

Chung, P. P. Y. (2011). Service leadership definitions. http://hki-slam.org/index.php?r=article\&catid=1\&aid= 11. Accessed July 152019.

Claar, V. V., Jackson, L., \& TenHaken, V. (2016). Are servant leaders born or made? Servant Leadership: Theory \& Practice, 1(1), 46-52.

Connelly, M. S., Gilbert, J. A., Zaccaro, S. J., Threlfall, K. V., Marks, M. A., \& Mumford, M. D. (2000). Exploring the relationship of leadership skills and knowledge to leader performance. The Leadership Quarterly, 11(1), 65-86. https://doi.org/10.1016/S1048-9843(99)00043-0.

Cress, C. M., Astin, H. S., Zimmerman-Oster, K., \& Burkhardt, J. C. (2001). Developmental outcomes of college students' involvement in leadership activities. Journal of College Student Development, 42(1), 1527.

Diener, E., Emmons, R. A., Larsen, R. J., \& Griffin, S. (1985). The satisfaction with life scale. Journal of Personality Assessment, 49(1), 71-75. https://doi.org/10.1207/s15327752jpa4901 13.

Dugan, J. P., \& Komives, S. R. (2007). Developing leadership capacity in college students: Findings from a national study. College Park, MD: National Clearinghouse for Leadership Programs.

Fagginger Auer, M., Hickendorff, M., \& van Putten, C. M. (2018). Training can increase students' choices for written solution strategies and performance in solving multi-digit division problems. Frontiers in Psychology, 9, 1644. https://doi.org/10.3389/fpsyg.2018.01644.

Goertzen, B. J., \& Whitaker, B. L. (2015). Development of psychological capital in an academic-based leadership education program. Journal of Management Development, 34(7), 773-786. https://doi.org/10. 1108/JMD-07-2013-0100.

Gooty, J., Connelly, S., Griffith, J., \& Gupta, A. (2010). Leadership, affect and emotions: A state of the science review. The Leadership Quarterly, 21(6), 979-1004. https://doi.org/10.1016/j.leaqua.2010.10. 005 .

Grönfeldt, S., \& Strother, J. B. (2006). Service leadership: The quest for competitive advantage. California, CA: SAGE.

Haber, P. (2006). Structure, design, and models of student leadership programs. In S. R. Komives, J. P. Dugan, J. E. Owen, C. Slack, \& W. Wagner (Eds.), Handbook for student leadership programs (pp. 29-51). College Park: National Clearinghouse for Leadership Programs.

Hakanen, A., \& Van Dierendonck, D. (2011). Servant leadership and life satisfaction: The mediating role of justice, job control, and burnout. The International Journal of Servant-Leadership, 7(1), 253-261.

Hausler, M., Strecker, C., Huber, A., Brenner, M., Höge, T., \& Höfer, S. (2017). Distinguishing relational aspects of character strengths with subjective and psychological well-being. Frontiers in Psychology, 8(1159). https://doi.org/10.3389/fpsyg.2017.01159.

Hoshmand, A. R. (2015). The role of service leadership in the university's GE curriculum: The HKBU experience. In D. T. L. Shek \& P. P. Y. Chung (Eds.), Promoting service leadership qualities in university students (Vol. 6, pp. 17-28, Quality of life in Asia). Singapore: Springer.

Klimstra, T. A., Bleidorn, W., Asendorpf, J. B., Van Aken, M. A., \& Denissen, J. J. (2013). Correlated change of big five personality traits across the lifespan: A search for determinants. Journal of Research in Personality, 47(6), 768-777. https://doi.org/10.1016/j.jrp.2013.08.004.

Kolb, D. A. (2014). Experiential learning: Experience as the source of learning and development (2nd ed.). Upper Saddle River, NJ: FT Press.

Komives, S. R., Owen, J. E., Longerbeam, S. D., Mainella, F. C., \& Osteen, L. (2005). Developing a leadership identity: A grounded theory. Journal of College Student Development, 46(6), 593-611. https://doi.org/10.1353/csd.2005.0061.

Kucsera, J. V., \& Zimmaro, D. M. (2010). Comparing the effectiveness of intensive and traditional courses. College Teaching, 58(2), 62-68.

Kuoppala, J., Lamminpää, A., Liira, J., \& Vainio, H. (2008). Leadership, job well-being, and health effectsA systematic review and a meta-analysis. Journal of Occupational and Environmental Medicine, 50(8), 904-915. https://doi.org/10.1097/JOM.0b013e31817e918d. 
Lin, L., \& Shek, D. T. L. (2018). Does service leadership education contribute to student well-being? A quasiexperimental study based on Hong Kong university students. Applied Research in Quality of Life, 14, 1147-1163. https://doi.org/10.1007/s11482-018-9644-x.

Lo, S. M., Wong, H. C., Lam, C. Y., \& Shek, D. T. L. (2018). Common mental health challenges in a university context in Hong Kong: A study based on a review of medical records. Applied Research in Quality of Life. https://doi.org/10.1007/s11482-018-9673-5.

Lo, S. M., Wong, H. C., Lam, C. Y., \& Shek, D. T. L. (2019). An innovative multidisciplinary healthcare model in student mental health: Experience in Hong Kong. Applied Research in Quality of Life. https:// doi.org/10.1007/s11482-019-09770-9.

Ma, C. M. S., Shek, D. T. L., \& Chen, J. M. (2019). Changes in the participants in a community-based positive youth development program in Hong Kong: Objective outcome evaluation using a one-group pretestposttest design. Applied Research in Quality of Life, 14, 961-979. https://doi.org/10.1007/s11482-0189632-1.

Mathieson, K. (1991). Predicting user intentions: Comparing the technology acceptance model with the theory of planned behavior. Information Systems Research, 2(3), 173-191. https://doi.org/10.1287/isre.2.3.173.

McElwain, A., Finnegan, V., Whittaker, A., Kerpelman, J., Adler-Baeder, F., \& Duke, A. (2016). Evaluation and lessons learned from an undergraduate service learning course providing youth-focused relationship education. Evaluation and Program Planning, 58, 116-124. https://doi.org/10.1016/j.evalprogplan.2016. 06.002 .

Pandya, T., Dirks, R., \& Kwok, A. (2017). Leaders are made, not born: A leadership development curriculum for general surgery residents. Journal of the American College of Surgeons, 225(4), e154-e155. https:// doi.org/10.1016/j.jamcollsurg.2017.07.945.

Riggio, R. E., Ciulla, J., \& Sorenson, G. (2003). Leadership education at the undergraduate level: A liberal arts approach to leadership development. In S. E. Murphy \& R. E. Riggio (Eds.), The future of leadership development (pp. 223-236). Mahwah, NJ: Lawrence Erlbaum Associates.

Rimal, R. N. (2000). Closing the knowledge-behavior gap in health promotion: The mediating role of selfefficacy. Health Communication, 12(3), 219-237. https://doi.org/10.1207/S15327027HC1203_01.

Roberts, C. (2013). Building social capital through leadership development. Journal of Leadership Education, $12,54-73$.

Roberts, C., \& Westville, I. (2008). Developing future leaders: The role of reflection in the classroom. Journal of Leadership Education, 7(1), 116-130.

Rosch, D. M., \& Caza, A. (2012). The durable effects of short-term programs on student leadership development. Journal of Leadership Education, 11(1), 28-48.

Sánchez-Mendiola, M., Martínez-Franco, A. I., Lobato-Valverde, M., Fernández-Saldívar, F., Vives-Varela, T., \& Martínez-González, A. (2015) Evaluation of a biomedical informatics course for medical students: A pre-posttest study at UNAM Faculty of medicine in Mexico. BMC Medical Education, 15(1), article 64, doi:https://doi.org/10.1186/s12909-015-0349-7.

Sartori, R., Costantini, A., Ceschi, A., \& Tommasi, F. (2018). How do you manage change in organizations? Training, development, innovation, and their relationships. Frontiers in Psychology, 9, 313. https://doi. org/10.3389/fpsyg.2018.00313.

Scamardo, M., \& Harnden, S. C. (2007). A manager coaching group model: Applying leadership knowledge. Journal of Workplace Behavioral Health, 22(2-3), 127-143. https://doi.org/10.1300/J490v22n03_09.

Scott, P. A. (2003). Attributes of high-quality intensive courses. New Directions for Adult and Continuing Education, 2003(97), 29-38.

Shek, D. T. L., \& Chai, W. Y. (2019). Psychometric properties of the service leadership attitude scale in Hong Kong. Frontiers in Psychology, 10, 1070. https://doi.org/10.3389/fpsyg.2019.01070.

Shek, D. T. L., Chung, P. P. Y., \& Leung, H. (2015). How unique is the service leadership model? A comparison with contemporary leadership approaches. International Journal on Disability and Human Development, 14(3), 217-231. https://doi.org/10.1515/ijdhd-2015-0403.

Shek, D. T. L., Chung, P. P. Y., Lin, L., Leung, H., \& Ng, E. (2018a). Service leadership under the service economy. In J. L. Chin, J. E. Trimble, \& J. E. Garcia (Eds.), Global and culturally diverse leaders and leadership: New dimensions and challenges for business, education and society (pp. 143-161). Bingley, UK: Emerald Publishing.

Shek, D. T. L., Dou, D., \& Ma, L. K. (2019). Development and validation of a pioneer scale on service leadership behavior in the service economies. Frontiers in Psychology, 10, 1770. https://doi.org/10.3389/ fpsyg.2019.01770.

Shek, D. T. L., \& Lin, L. (2015). Evaluating service leadership programs with multiple strategies. In D. T. L. Shek \& P. P. Y. Chung (Eds.), Promoting service leadership qualities in university students (pp. 197212). Singapore: Springer. 
Shek, D. T. L., \& Lin, L. (2016). Changes in university studetns after joining a service leadership program in China. Journal of Leadership Education, 15(1), 96-109, doi:1012806/V15/I1/A2.

Shek, D. T. L., Lin, L., \& Leung, H. (2018b). Objective outcome evaluation of service leadership education for university students in Hong Kong. International Journal on Disability and Human Development, 17(1), 119-124.

Shek, D. T. L., Ma, C. M. S., \& Merrick, J. (2016). Nurturing university students to be tomorrow's leaders. International Journal on Disability and Human Development, 15(2), 125-126. https://doi.org/10.1515/ ijdhd-2016-0700.

Shek, D. T. L., \& Ng, E. C. W. (2017). Leadership training for university students in Hong Kong: A critical review. International Journal of Child and Adolescent Health, 10(1), 25-40.

Shek, D. T. L., \& Sun, R. C. F. (2008). Implementation of a positive youth development program in a Chinese context: The role of policy, program, people, process, and place. The Scientific World Journal, 8, 980996. https://doi.org/10.1100/tsw.2008.120.

Shek, D. T. L., \& Sun, R. C. F. (2012). Promoting psychosocial competencies in university students: Evaluation based on a one-group pre-test/post-test design. International Journal on Disability and Human Development, 11(3), 229-234. https://doi.org/10.1515/ijdhd-2012-0039.

Shek, D. T. L., Yu, L., Ma, C. M. S., Sun, R. C. F., \& Liu, T. T. (2013). Development of a credit-bearing service leadership subject for university students in Hong Kong. International Journal of Adolescent Medicine and Health, 25(4), 353-361. https://doi.org/10.1515/ijamh-2013-0033.

Shek, D. T. L., Yu, L., Wu, F. K. Y., Zhu, X., \& Chan, K. H. Y. (2017). A 4-year longitudinal study of wellbeing of Chinese university students in Hong Kong. Applied Research in Quality of Life, 12(4), 867-884. https://doi.org/10.1007/s11482-016-9493-4.

Shek, D. T. L., \& Zhu, X. (2018). Pretest-posttest designs. In B. Frey (Ed.), The SAGE encyclopedia of educational research, measurement, and evaluation (pp. 1293-1295). Thousand Oaks, CA: Sage Publications.

Shek, D. T. L., Zhu, X., \& Zhu, A. Y. F. (2018c). Conceptual background and the development of service leadership knowledge scale. International Journal of Child and Adolescent Health, 11(4), 395-404.

Singh, A., \& Jaykumar, P. (2019). On the road to consensus: Key soft skills required for youth employment in the service sector. Worldwide Hospitality and Tourism Themes, 11(1), 10-24. https://doi.org/10.1108/ WHATT-10-2018-0066.

Slavec, A., \& Drnovsek, M. (2012). A perspective on scale development in entrepreneurship research. Economic and Business Review, 14(1), 39-62.

Snell, R. S., Chan, M. Y. L., Ma, C. H. K., \& Chan, C. K. M. (2015). A road map for empowering undergraduates to practice service leadership through service-learning in teams. Journal of Management Education, 39(3), 372-399. https://doi.org/10.1177/1052562914545631.

Stephens, C. M., \& Beatty, C. C. (2015). Leading and thriving: How leadership education can improve firstyear student success. Journal of Leadership Education, 14(3), 119-131, doi:1012806/V14/I3/T1.

The World Bank (2019). Services, etc., value added (\% of GDP). https://data.worldbank.org/indicator/NV. SRV.TOTL.ZS. Accessed July 152019.

Thyer, B. A. (2002). Evaluation of social work practice in the new millennium: Myths and realities. In D. T. L. Shek, M. C. Lam, C. F. Au, \& L. J. J (Eds.), Advances in social welfare service and research (pp. 3-18). Hong Kong: New Asia college and the Chinese University press, the Chinese University of Hong Kong.

Wang, A. C., \& Cheng, B. S. (2010). When does benevolent leadership lead to creativity? The moderating role of creative role identity and job autonomy. Journal of Organizational Behavior, 31(1), 106-121. https:// doi.org/10.1002/job.634.

Wong, L., \& Chandra, Y. (2015). Service leadership education embedded in a social innovation and entrepreneurship framework. In D. T. L. Shek \& P. P. Y. Chung (Eds.), Promoting service leadership qualities in university students (Vol. 6, pp. 51-65, Quality of life in Asia). Singapore: Springer.

Yang, Y. T. C., Chuang, Y. C., Li, L. Y., \& Tseng, S. S. (2013). A blended learning environment for individualized English listening and speaking integrating critical thinking. Computers and Education, 63, 285-305. https://doi.org/10.1016/j.compedu.2012.12.012.

Yang, Y. T. C., Gamble, J. H., Hung, Y. W., \& Lin, T. Y. (2014). An online adaptive learning environment for critical-thinking-infused English literacy instruction. British Journal of Educational Technology, 45(4), 723-747. https://doi.org/10.1111/bjet.12080.

Publisher's Note Springer Nature remains neutral with regard to jurisdictional claims in published maps and institutional affiliations. 